\title{
Application of Computer-Based Auto Accompaniment in Music Education
}

\author{
https://doi.org/10.3991/ijet.v15i06.13333 \\ Yifeng Li \\ Northeast Agricultural University, Harbin, China \\ Liyifeng1929@126.com
}

\begin{abstract}
The computer-based auto accompaniment (AA) reflects the integration between computer technology and music theory. If applied in music education, the computer-based AA may kindle the flame of innovation in music teaching and creation and reshape the traditional music teaching mode. Therefore, this paper probes deep into the value of applying the computer-based AA in music education. Firstly, the author discussed the merits and defects of the application. To disclose the application effect, the computer-based AA was introduced to the teaching of ten songs among 92 music majors. The test results were analysed in details. The results show that the computer-based AA can satisfy the requirements of music teaching, making the teaching objective easier to achieve; the students were very interested in the computer-based AA; the computer-based AA can adapt to various tones, melodies and chords, and thus suit different styles of music; the computer-based AA enjoys high feasibility and flexibility, and boasts high values in music teaching. The research findings lay a theoretical basis for applying computer arrangement in music teaching.
\end{abstract}

Keywords—Auto accompaniment (AA), computer technology, music theory, music education

\section{Introduction}

With the rapid development of computer technology, it has built bridges between music art and science and technology in the fields of electroacoustics, acoustics, recording technology and electronic information technology, and modern computer multimedia technology has been widely applied in a variety of fields such as music education, music creation and production, and music communication [1]. Meanwhile, there emerges an electronic audio processing software, which is changing the original methods and programs in music education [2]. At present, computer-based AA, as a new direction in the field of artificial intelligence, is a computer-based process of intelligently simulating the human's melody accompaniment according to the theme of song melody [3]. This technology is fast, time-saving, labour-saving, and highly operable. It can enhance the power of music creation, and is also conducive to the improvement of computer software and automation [4]. 
Related theories of music show that music melody can exist alone, and accompaniment can help the melody express emotion more completely, thus giving the song a more vivid, prominent and infectious composition [5]. Computer-based AA follows the principle of algorithmic composition. The algorithmic composition is the algorithm-based technique of using small motivations or compositions to form a specific sequence or set of music by taking the comprehensive form of multiple basic elements of music as the core [6]. Besides, the computer-based AA can constitute a variety of changing forms. In this respect, humans are not comparable. During the process, the computer can exhaust all possible changes and choose to constitute a meaningful and aesthetically valuable music process [7]. In the music teaching process, this technique can enhance the fun of music learning, cultivate students' good inner hearing, and improve their creativity and imaginary control of music composition [8-9]. In view of the above, this paper attempts to explore the application value of computer-based AA technology in music education. This study provides a theoretical basis for the application of computer arrangement in music teaching.

\section{Merits and Defects of Applying the Computer Technology in Music Teaching}

\subsection{Merits of computer technology in music teaching}

If applied in music teaching, the computer technology can not only help to realize the audio-visual integration of music, and fully highlight the nature of music, but also ensure the music software to run quickly and conveniently, thus realizing the playing various sheet music over and over again with multiple sounds [10-11]. As the research deepens continuously, computer technology has gradually shown its practicality, comprehensiveness, and flexibility in music teaching. In music teaching and learning, accompaniment is the soul of music, while the computer technology can assist in the completion of music audio, video, and generation of sheet music, etc. [12]. In addition, it also provides recording, editing and processing of sounds, that is, audio extraction, sound editing, and standardization processing of sounds [13].

Figure 1 shows the merits of computer technology in music teaching. In terms of music knowledge, the computer technology enriches the teaching methods, improves the teaching quality, reduce the teaching difficulty, and accelerates the speed of teaching; the use of computer software for music theory teaching can also motivate students 'learning interest, thereby expanding their image thinking. In terms of music literacy, the application of computer software trains and develops students' musical listening ability, enhances their feelings of tone, rhythm, intensity, pitch, and timbre of sounds, effectively improve students' musical literacy, develop musical memory, and enhance their perception and understanding of music. In terms of musical skills, by comparing different melody of music, students can gradually build up correct sound concept. In terms of music appreciation, computer software can help improve students' music literacy and music appreciation ability. 


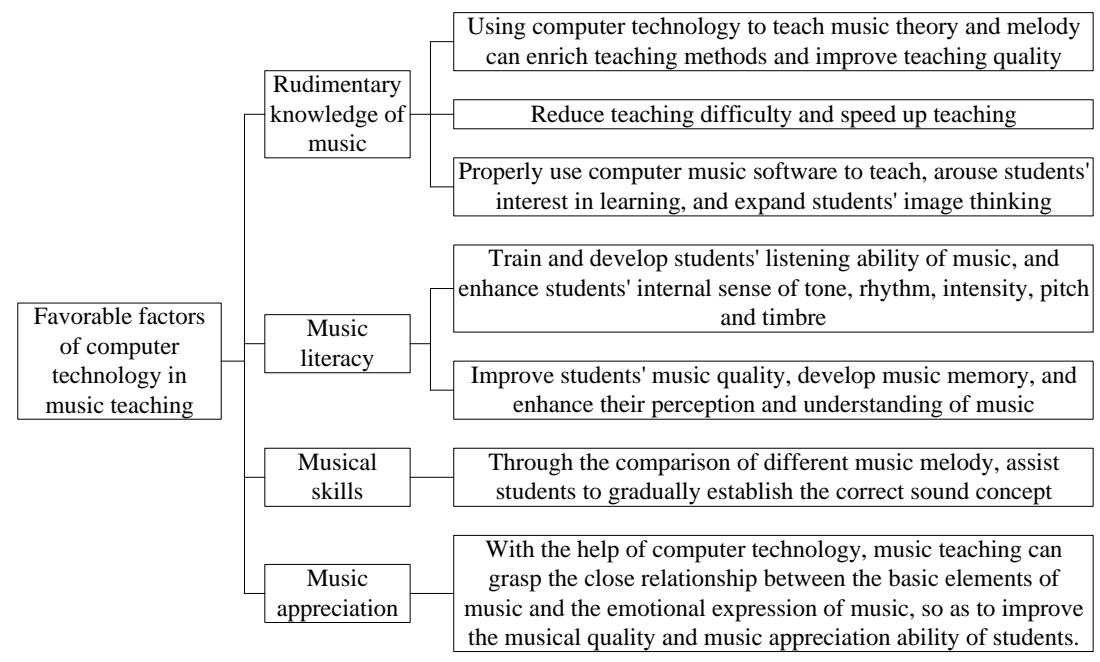

Fig. 1. Merits of computer technology in music teaching

\subsection{Defects of computer technology in music teaching}

Using computer technology, traditional music teaching has made breakthroughs in all aspects [14-15]. At present, computer technology is basically applied in most courses of music education, and it has also received more attention from teachers and students. Meanwhile, colleges and universities have gradually offered many computer-based music production courses [16-17]. However, there are still many defects in the application of current computer technology in music teaching (Figure 2). From the aspect of computer hardware, due to the limited objective conditions, there are insufficient multimedia classrooms in many areas, and not enough funds to purchase relevant hardware such as computer music systems; from the aspect of computer software, most schools do not use copyrighted software, but demo or trial versions, which results in some functions being limited and the weak experience; from the aspects of teachers, most teachers use software in the self-study and exploration stage, lacking theoretical knowledge of software, and formal operation training and guidance, etc. Also, teachers have a large daily workload and do not have a lot of time to make software courses. 


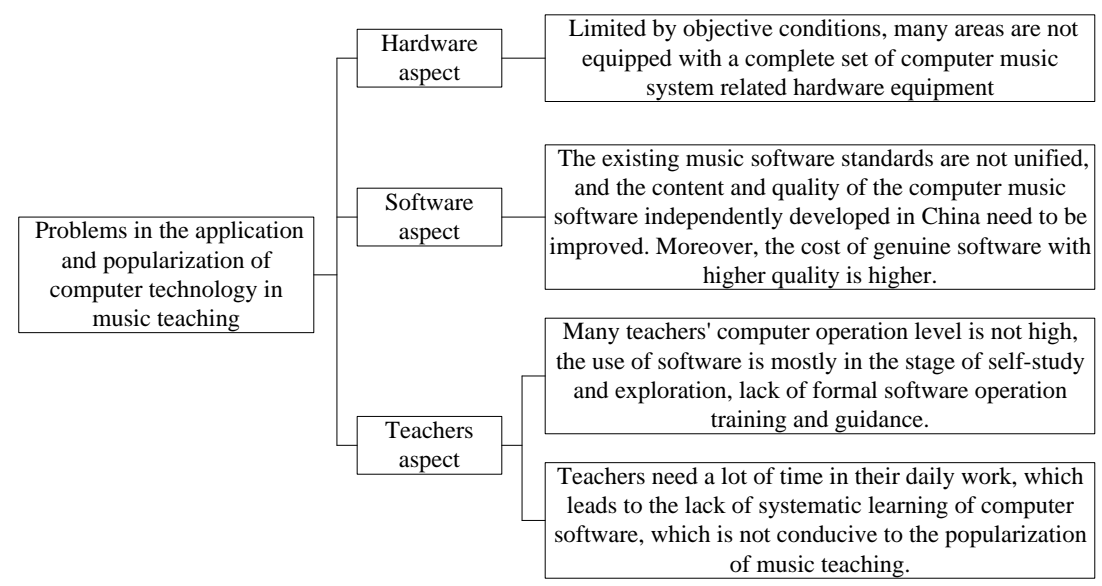

Fig. 2. Defects in the application and popularization of computer technology in music teaching

\section{Implementation and Evaluation of Computer-Based Auto Accompaniment}

\subsection{Analysis for implementation effect}

Currently, the popular AA software on the market is the Band in a Box system, and a real-time AA system is also built by Microsoft based on the hidden Markov model, but they differ greatly in styles [18-19]. The computer-based AA can help students to fully understand the tempo, beat, and note value under different accompaniment melody, and allow them to fully understand each time note in the production process of computer music software [20-21]. Melody, rhythm and harmony are the three major elements of the accompaniment. The harmony in the accompaniment enriches the form of the song. Table 1 lists the chord sequence; the harmony will connect the chords horizontally according to certain rules and certain order, and different chords are connected to form different harmony. Figure 3 shows the experiment flow chart of computer-based AA algorithm. Specifically, firstly the sample songs were entered, and the system recorded the accompaniment pattern of the existing sample songs into the data table and extract the relevant features. Then, according to the chord sequence algorithm, the energy scores of the accompaniment chords was calculated by fuzzy reasoning. The accompaniment pattern automatically acquired the chord algorithm and build the database of accompaniment pattern. Next, the matching degree was used to calculate the accompaniment pattern with the maximum matching value, and combine the chord and the accompaniment pattern for completing the accompaniment part. Before performing the automatic accompaniment, the computer needs to extract the accompaniment of the sample songs. Figure 4 shows the computer accompaniment recognition software.

To study the implementation effect of computer-based AA, ten songs were selected, and 92 college students majoring in music were selected as the respondents. The 
experiment was conducted on them in terms of the timbre, melody, tone, pitch, and chord, etc. Table 2 lists the song names for the experiment. Figure 5 shows the computer-based AA evaluation results. It can be clearly seen that college students' AA scores were higher than those under the traditional music accompaniment.

Table 1. Chord sequence

\begin{tabular}{|c|c|c|c|}
\hline First note & $\begin{array}{c}\text { Take the first note as the } \\
\text { root sound }\end{array}$ & $\begin{array}{c}\text { Take the first note as the } \\
\text { third note }\end{array}$ & $\begin{array}{c}\text { Take the first note as the } \\
\text { five note }\end{array}$ \\
\hline 1 & $1,3,5$ & $06,1,3$ & $04,06,1$ \\
\hline 2 & $2,4,6$ & $07,2,4$ & $05,07,2$ \\
\hline 3 & $3,5,7$ & $1,3,5$ & $06,1,3$ \\
\hline 4 & $4,6,11$ & $2,4,6$ & $07,2,4$ \\
\hline 5 & $5,7,12$ & $3,5,7$ & $1,3,5$ \\
\hline 6 & $6,11,13$ & $4,6,11$ & $2,4,6$ \\
\hline 7 & $7,12,14$ & $5,7,12$ & $3,5,7$ \\
\hline
\end{tabular}

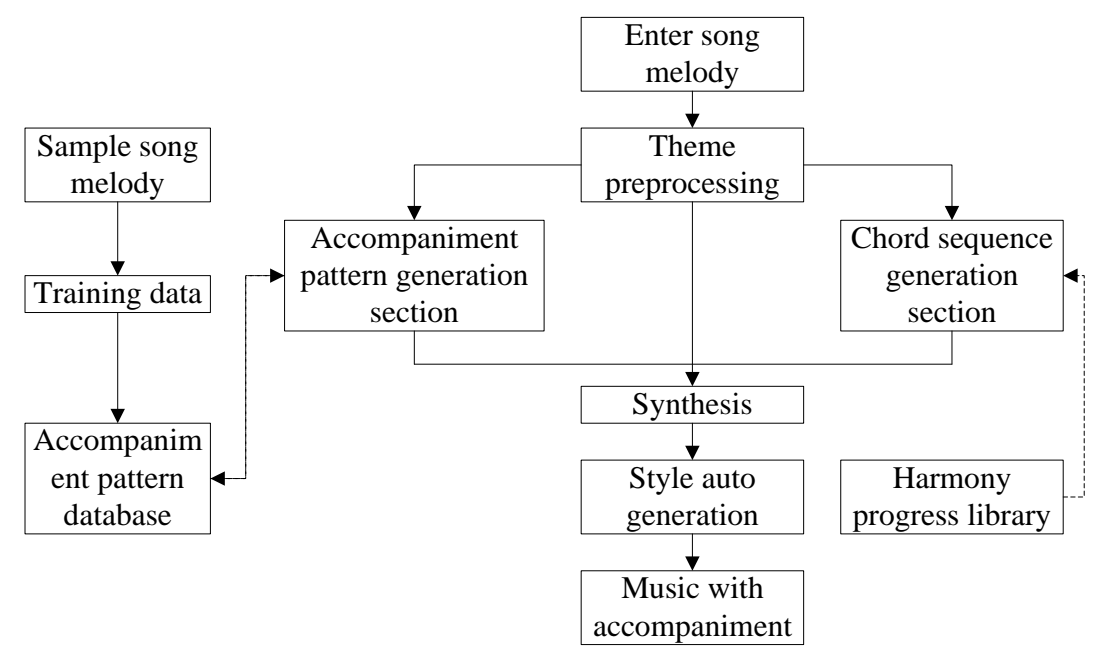

Fig. 3. Experimental flow chart of computer automatic accompaniment algorithm 


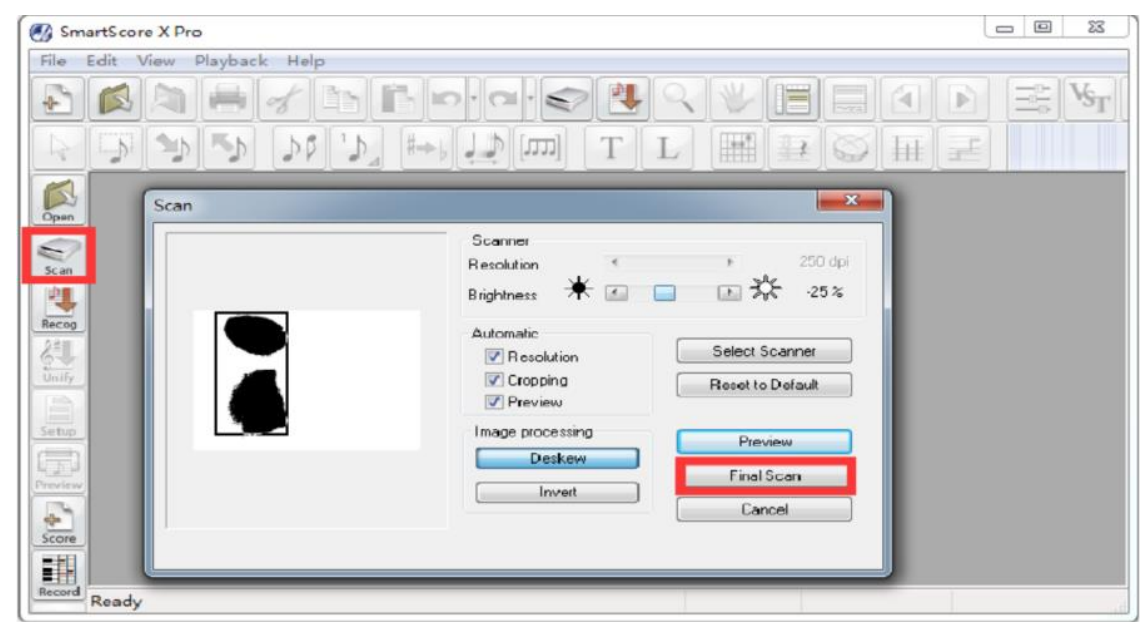

Fig. 4. Computer accompaniment recognition software

Table 2. Experimental song name

\begin{tabular}{|c|l|c|l|}
\hline No. & \multicolumn{1}{|c|}{ Song } & No. & \multicolumn{1}{c|}{ Song } \\
\hline 1 & Qing Zang Gao Yuan & 6 & Shan Tan Wang Shi \\
\hline 2 & Beijing De Jin Shan Shang & 7 & Qing Shi Zhi Lian \\
\hline 3 & Shuo San Jiu San & 8 & Zhuo Ma \\
\hline 4 & Deng Ni Xia Ke & 9 & Tian Lu \\
\hline 5 & Bing Xue Tian Tang & 10 & Lao Shu Ai Da Mi \\
\hline
\end{tabular}

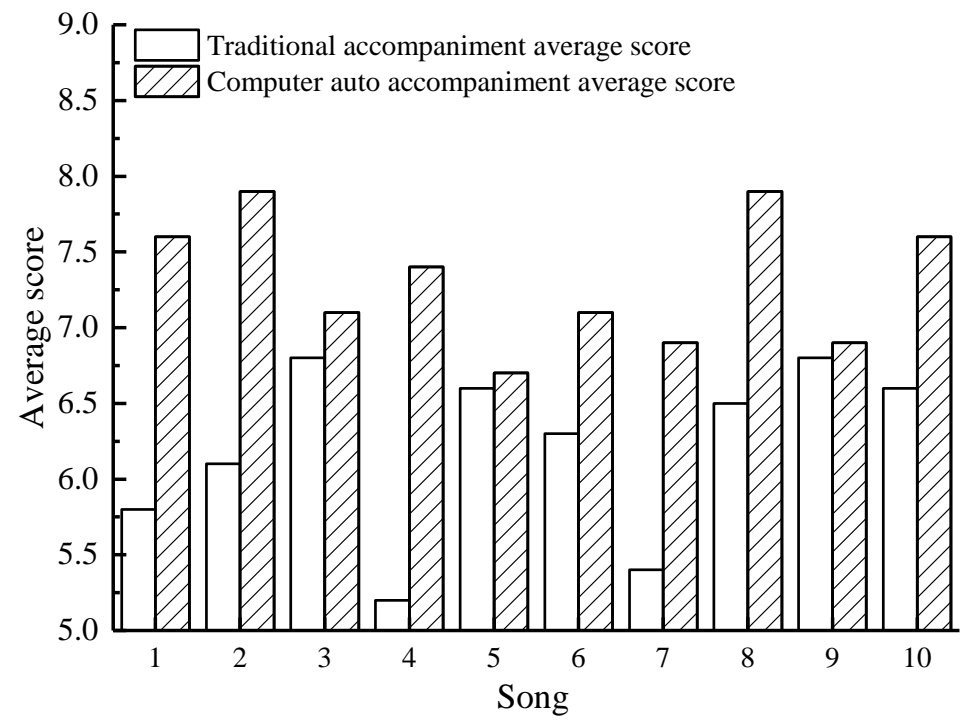

Fig. 5. Evaluation results of computer auto accompaniment 


\subsection{Curriculum practice evaluation}

Through the analysis for the implementation effect of the computer-based AA, it's found that this technology can meet the requirements of music teaching, and make it easy to achieve the teaching goals. Also, most students can complete the classroom learning tasks well, and show very high interest in computer-based AA. Figure 6 evaluates the students' preference for traditional or computer-based accompaniment in music education. By comparing the traditional accompaniment in Figure 6 (a) with the computer-based one in Figure 6 (b), it can be found that college students had a higher probability of liking computer-based accompaniment than the traditional one, and the probability of disliking computer-based accompaniment was significantly reduced. Figure 7 shows the main flow of the computer-based AA accompaniment system in the training stage. The entire process is to achieve a fuzzy match between the sample accompaniment and the database. The information such as rhythm, tempo, and mode were determined by the melody, and the sample spectrum was segmented into sections or parts of sounds etc. After the sample spectral state segmentation, they're converted it into a phonetic structure and stored in the database. Finally, the rhythm sequence and harmony sequence were compared to complete the computerbased AA training.

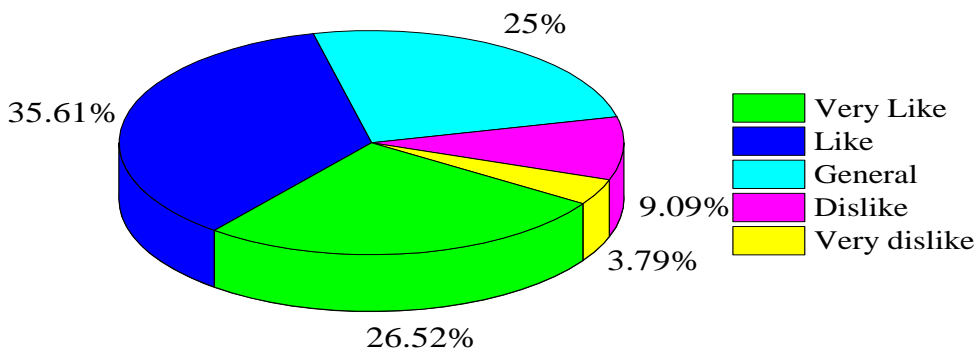

(a) Traditional music accompaniment

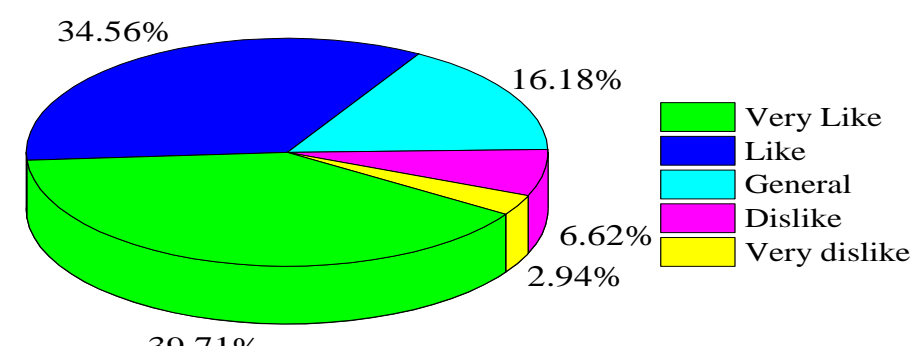

$39.71 \%$

(b) Computer independent accompaniment

Fig. 6. Analysis of preference evaluation of traditional and computer aided accompaniment music education 


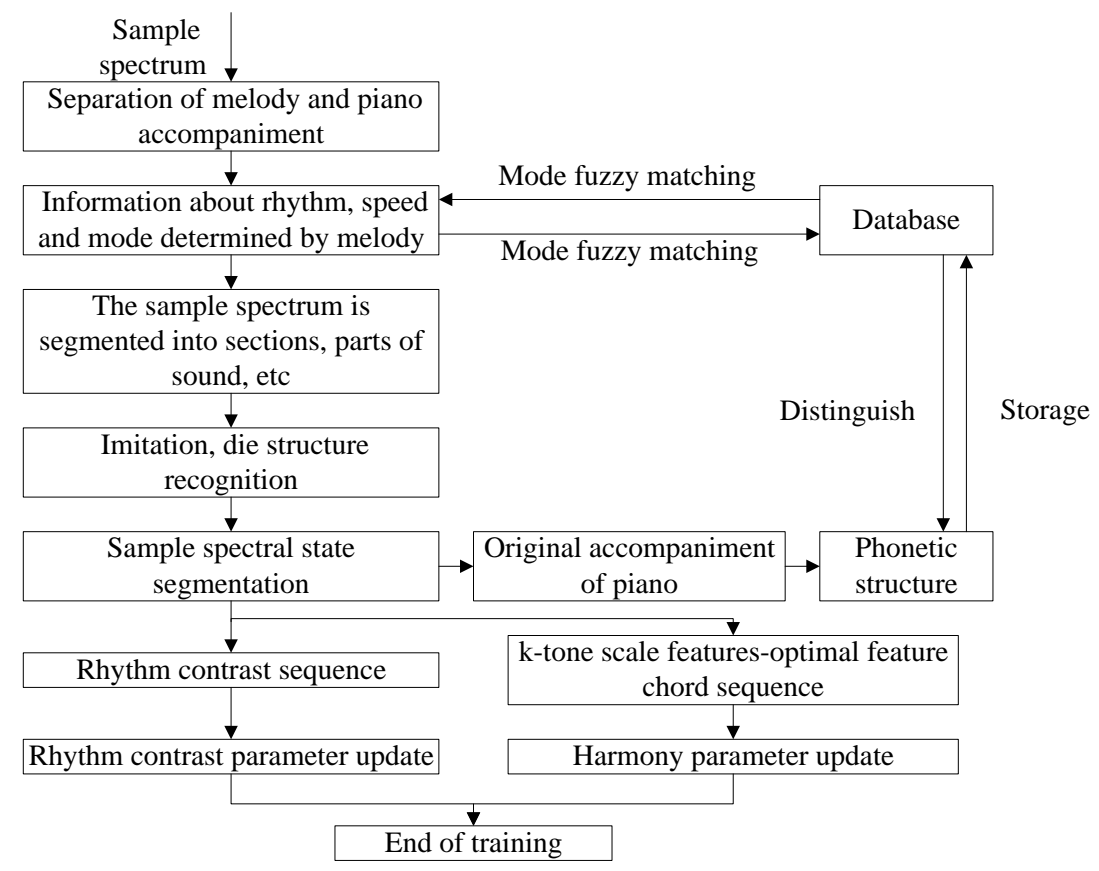

Fig. 7. Main process of music auto accompaniment system in training stage

\section{Application Value of Computer-Based Auto Accompaniment in Music Teaching}

\subsection{Application of computer-based AA in music teaching}

Students at different stages have different musical cognition, while music cognition is also correlated with psychological development. In the generation process of computer-based AA, the chords and sound patterns of each accompaniment do not correspond one-to-one, but only to several types of accompaniment patterns. During the database matching process, the accompaniment pattern with the highest probability corresponding to chords was selected as the one for chord accompaniment. Figure 8 shows the auto generating graph of computer-based AA, in which the melody and chord features of the sample songs were firstly extracted and the chord energy score was calculated; then, the chord sequence was extracted to match the accompaniment pattern database; finally, the accompaniment was automatically generated through the matching algorithm of the accompaniment pattern.

In music teaching, heuristic teaching is an important method for cultivating students' creative ability. For college students who study music arrangement, computerbased AA can match all kinds of different tones, melody and chords to inspire their creative ability. The entire AA process does not require specific design. It may not show a strong sense of the form of work, but provides a good creative inspiration for 
music lovers. In the creative process, one can obtain different styles of music accompaniment by randomly switching the accompaniment type.

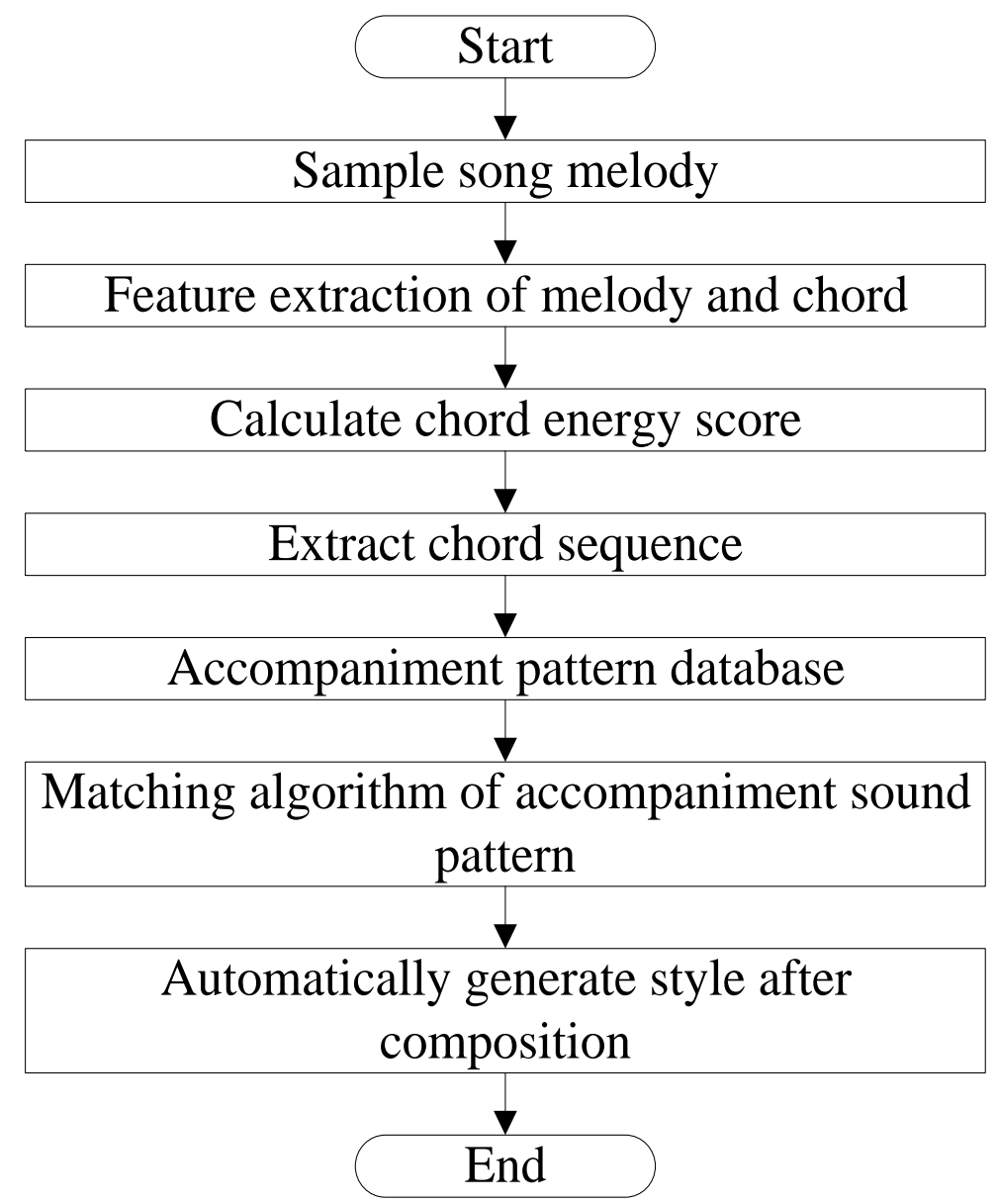

Fig. 8. Computer style auto generating graph

\subsection{Significance for applying the computer-based auto accompaniment in music teaching}

Computer-based AA has strong practicality. Through repeated practice of "accompaniment-chord, chord-accompaniment", students can make improvements. Besides, flexibility is another advantage of computer-aided AA, e.g., students show strong flexibility in learning methods and styles. Figure 9 shows the significance of computer-based AA technology applied to music teaching. Specifically, this can stimulate students' interest in music learning, keep attention in music teaching classrooms, improve perceptual efficiency, increase the efficiency of music memory in the process of 
music learning, and cultivate their musical learning creativity and sensitivity to music harmony; also, train students' ability of harmony hearing, help students to conduct music harmony analysis training, understand different music harmony styles; continue the classroom, realize the self-help learnings of students, and improve students' enthusiasm to complete homework.

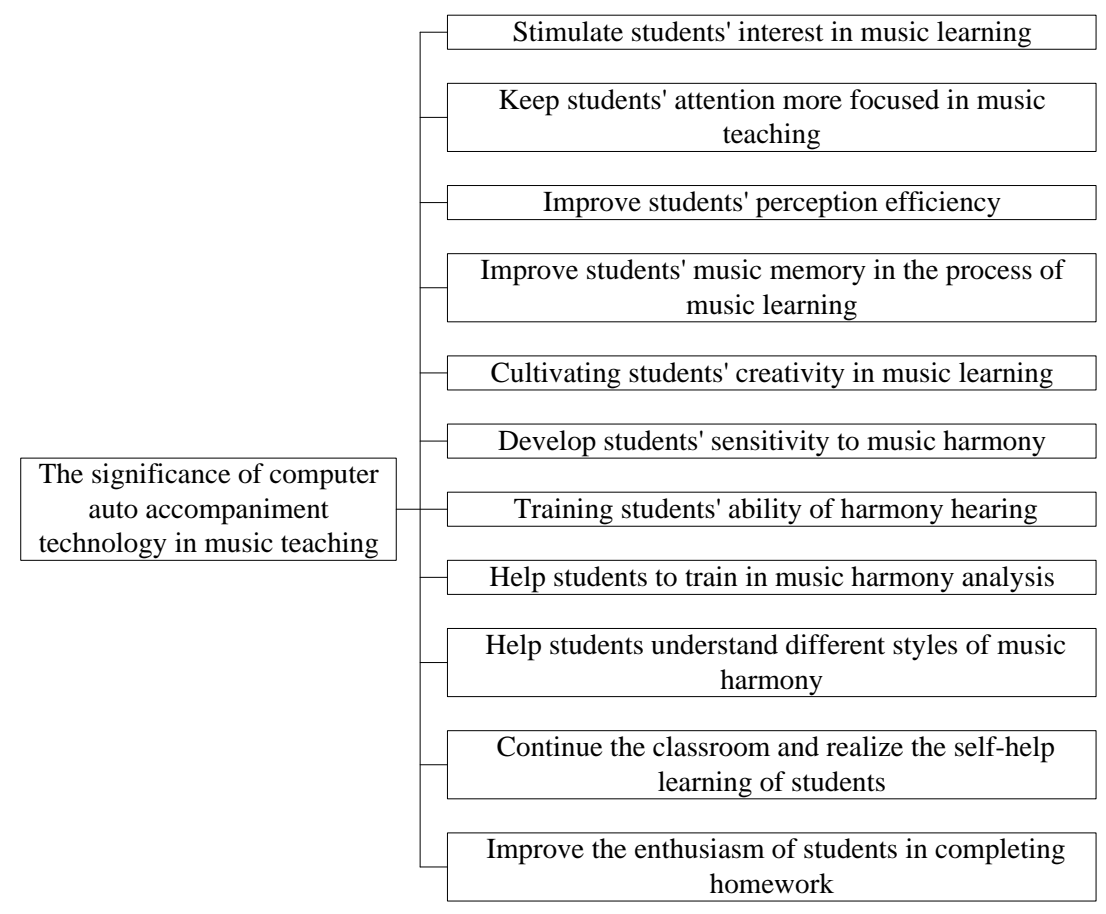

Fig. 9. The significance of computer auto accompaniment technology in music teaching

\section{Conclusion}

This paper explores the application of computer-based AA in music education, and analyses its application value. The specific conclusions are as follows:

- The merits of computer technology in music teaching are mainly reflected in the aspects of music knowledge, music literacy, music skills and music appreciation. However, its popularization and application are limited from the aspects of computer hardware, computer software, and teachers.

- The study found that most students can complete the classroom learning tasks well, show very high interest in computer-based AA; also, college students scored higher on computer-based AA than traditional accompaniment.

- The computer-based AA can match various tones, melody and chords, to inspire the creative ability of college students. The entire AA process does not require specific design. It may not show a strong sense of the form of work, but provides a 
good creative inspiration for music lovers. In the creative process, one can obtain different styles of music accompaniment by randomly switching the accompaniment type.

\section{Acknowledgement}

Name of higher education teaching project in Heilongjiang province: "Reform and promotion of Russian bel canto singing method in bel canto teaching in music colleges and universities" (Project No.: SJGY20170007) stage results.

\section{$7 \quad$ References}

[1] Silla, C. N., Przybysz, A. L., Leal, W. V. (2016). Music education meets computer science and engineering education. In 2016 IEEE Frontiers in Education Conference (FIE), 1-7. https://doi.org/10.1109/fie.2016.7757413

[2] Peterson, J., Haynes, G. (2017). Integrating Computer Science into Music Education. In Proceedings of the 2017 ACM SIGCSE Technical Symposium on Computer Science Education, 459-464. https://doi.org/10.1145/3017680.3017767

[3] Moore, D. (2014). Supporting students in music technology higher education to learn computer programming. Journal of Music, Technology \& Education, 7(1): 75-92. https:// doi.org/10.1386/jmte.7.1.75_1

[4] Seddon, F. A. (2006). Collaborative computer-mediated music composition in cyberspace. British Journal of Music Education, 23(3): 273-283. https://doi.org/10.1017/s02650517060 $\underline{07054}$

[5] Nikolaidou, G. N. (2012). ComPLuS model: A new insight in pupils' collaborative talk, actions and balance during a computer-mediated music task. Computers \& Education, 58(2): 740-765. https://doi.org/10.1016/j.compedu.2011.09.027

[6] Shapiro, R. B., Kelly, A., Ahrens, M., Johnson, B., Politi, H., Fiebrink, R. (2017). Tangible distributed computer music for youth. Computer Music Journal, 41(2): 52-68. https://doi. org/10.1162/comj_a_00420

[7] Cano, E., Schuller, G., Dittmar, C. (2014). Pitch-informed solo and accompaniment separation towards its use in music education applications. EURASIP Journal on Advances in Signal Processing, 2014(1): 23. https://doi.org/10.1186/1687-6180-2014-23

[8] Sheldon, D. A., Reese, S., Grashel, J. (1999). The effects of live accompaniment, intelligent digital accompaniment, and no accompaniment on musicians' performance quality. Journal of Research in Music Education, 47(3): 251-265. https://doi.org/10.2307/ $\underline{3345783}$

[9] Kersten, F. (2004). Using MIDI accompaniments for music learning at school and at home. Music Educators Journal, 90(4): 44-49. https://doi.org/10.2307/3399998

[10] Simeon, J. J. C., Ku, A. C. M. (2015). Effects of music instruction with bamboo xylophone accompaniment on singing achievement among second-grade children. Update: Applications of Research in Music Education, 33(2): 13-19. https://doi.org/10.1177/87551 $\underline{23314540660}$

[11] Dannenberg, R. B., Raphael, C. (2006). Music score alignment and computer accompaniment. Communications of the ACM, 49(8): 38-43. https://doi.org/10.1145/114 $\underline{5287.1145311}$ 
[12] Vurkaç, M. (2011). Clave-direction analysis: A new arena for educational and creative applications of music technology. Journal of Music, Technology \& Education, 4(1): 27-46. https://doi.org/10.1386/jmte.4.1.27_1

[13] Dannenberg, R.B. (1999). Intelligent computer accompaniment systems. The Journal of the Acoustical Society of America, 106(4): 2161.

[14] Davis, S. G., Blair, D. V. (2011). Popular music in American teacher education: A glimpse into a secondary methods course. International Journal of Music Education, 29(2): 124140. https://doi.org/10.1177/0255761410396962

[15] Berry, T. R. (2005). Black on Black education: Personally engaged pedagogy for/by African American pre-service teachers. The Urban Review, 37(1): 31-48. https://doi.org/ 10.1007/s11256-005-3560-8

[16] Jaschke, A. C., Eggermont, L. H., Honing, H., Scherder, E. J. (2013). Music education and its effect on intellectual abilities in children: a systematic review. Reviews in the Neurosciences, 24(6): 665-675. https://doi.org/10.1515/revneuro-2013-0023

[17] Dekker, M. C., Ziermans, T. B., Swaab, H. (2016). The impact of behavioural executive functioning and intelligence on math abilities in children with intellectual disabilities. Journal of Intellectual Disability Research, 60(11): 1086-1096. https://doi.org/10.1111/jir.1 $\underline{2276}$

[18] Fitzpatrick, K. R. (2016). Points of convergence in music education: The use of data labels as a strategy for mixed methods integration. Journal of Mixed Methods Research, 10(3): 273-291. https://doi.org/10.1177/1558689814560264

[19] Lawson Borders, G. (2003). Integrating new media and old media: Seven observations of convergence as a strategy for best practices in media organizations. International Journal on Media Management, 5(2): 91-99. https://doi.org/10.1080/14241270309390023

[20] Davis, S. G., Blair, D. V. (2011). Popular music in American teacher education: A glimpse into a secondary methods course. International Journal of Music Education, 29(2): 124140. https://doi.org/10.1177/0255761410396962

[21] Kremer Hayon, L. (1998). Teaching and teacher education: A glimpse into the future. Scandinavian Journal of Educational Research, 42(4): 377-388. https://doi.org/10.1080/0 $\underline{031383980420404}$

\section{Author}

Yifeng Li graduated from music college of China with a master's degree. He works in the school of art of northeast agricultural university and is engaged in opera singing and teaching. He has published many core papers. His research interests include electronic digital music, multimedia music technology and music education and teaching management.

Article submitted 2020-01-22. Resubmitted 2020-02-23. Final acceptance 2020-02-23. Final version published as submitted by the authors. 